
\title{
28 Research Suare \\ Multiple shoot induction in zygotic embryos: A strategy for acceleration of banana breeding
}

Backiyarani Suthanthiram ( $\sim$ backiyarani@gmail.com )

National Research Centre for Banana https://orcid.org/0000-0003-4122-5970

Uma Subbaraya

National Research Centre for Banana

Saranya Swaminathan

National Research Centre for Banana

Durai Palani

National Research Centre for Banana

Eugin Perianayagaraj Selvaraj

National Research Centre for Banana

Selvaraj Vadivel

National Research Centre for Banana

Saraswathi Marimuthu Somasundram

National Research Centre for Banana

Karthic Raju

National Research Centre for Banana

\section{Research Article}

Keywords: Banana breeding, Embryo culture, Regeneration efficiency, multiple shoots, Decortications

Posted Date: February 23rd, 2021

DOI: https://doi.org/10.21203/rs.3.rs-204075/v1

License: (c) (i) This work is licensed under a Creative Commons Attribution 4.0 International License.

Read Full License 


\section{Abstract}

The presence of residual female fertility in most of the parthenocarpic banana accessions, embryo culture technique encourages the banana breeder to develop new hybrids through conventional breeding. Desirable trait can be fixed in banana in the first generation of hybrid progenies, but their evaluation is a long process owing to non-availability of uniform suckers/planting material. The duration of the breeding cycle can be reduced by developing more number of plantlets per hybrid event under in vitro embryo culture. Thus efforts were taken to standardize the multiple shoot formation from single embryo through media manipulation and decortications of embryo culture derived single plants. Success on multiple shoot formation was achieved up to $75 \%$ and $95 \%$ in seeded accessions of M.acuminata and M.velutina embryos respectively. In general, enhanced regeneration efficiency and rate of multiple shoot formation were recorded in media with BAP concentration of $17.76 \mu \mathrm{m}$. Single in vitro plantlets derived through embryo culture were decorticated to 3 cubic $\mathrm{cm}$ size that resulted in $100 \%$ multiple shoot formations. This technique has been implemented from the seeds obtained from controlled pollination (18 cross combinations) and open pollination (nine accessions) of various genomic groups ( $A B B, A A B$, $A A)$ and their genetic fidelity of multiple shoots were also confirmed through microsatellite markers. As this technique, i) enhances the regeneration of hybrid seeds; ii) overcomes the risk of field mortality of the hybrid progenies and iii) allows simultaneous evaluation for multiple traits, will accelerate the breeding program by reducing the time taken for the release of potential banana hybrids.

\section{Full Text}

Due to technical limitations, full-text HTML conversion of this manuscript could not be completed. However, the manuscript can be downloaded and accessed as a PDF.

\section{Figures}



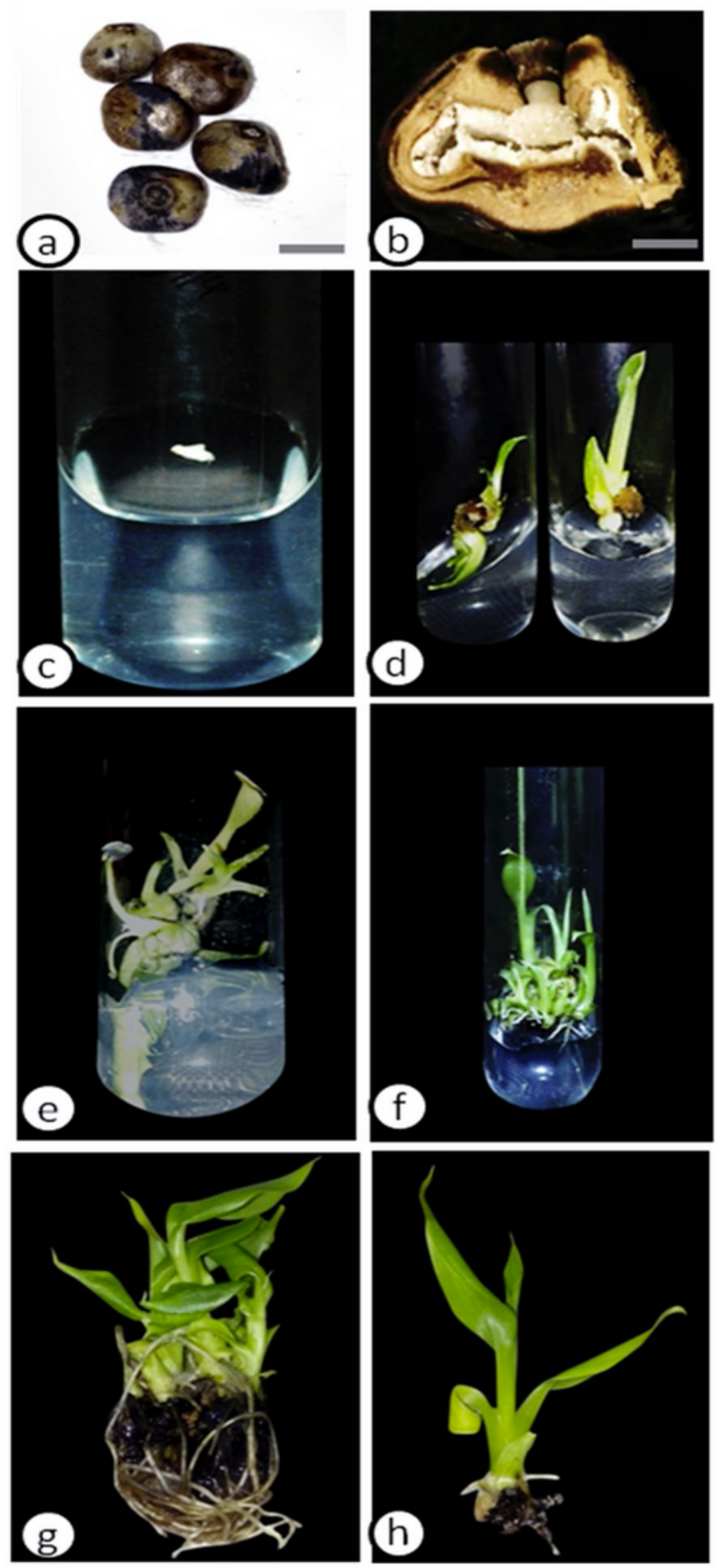

\section{Figure 1}

Embryo initiation in MS media supplemented with $17.76 \mu \mathrm{M}$ BAP a- Banana seeds, b-Cross section of seed with embryo and endosperm, c- Zygotic embryo initiation, $d$ - Initial multiple shoots arising from zygotic embryos, e-Multiple shoots formation after 50 days, f-Multiple shoots after 75 days, g-Shoot and root development, h- Regenerated plant ready for hardening. 

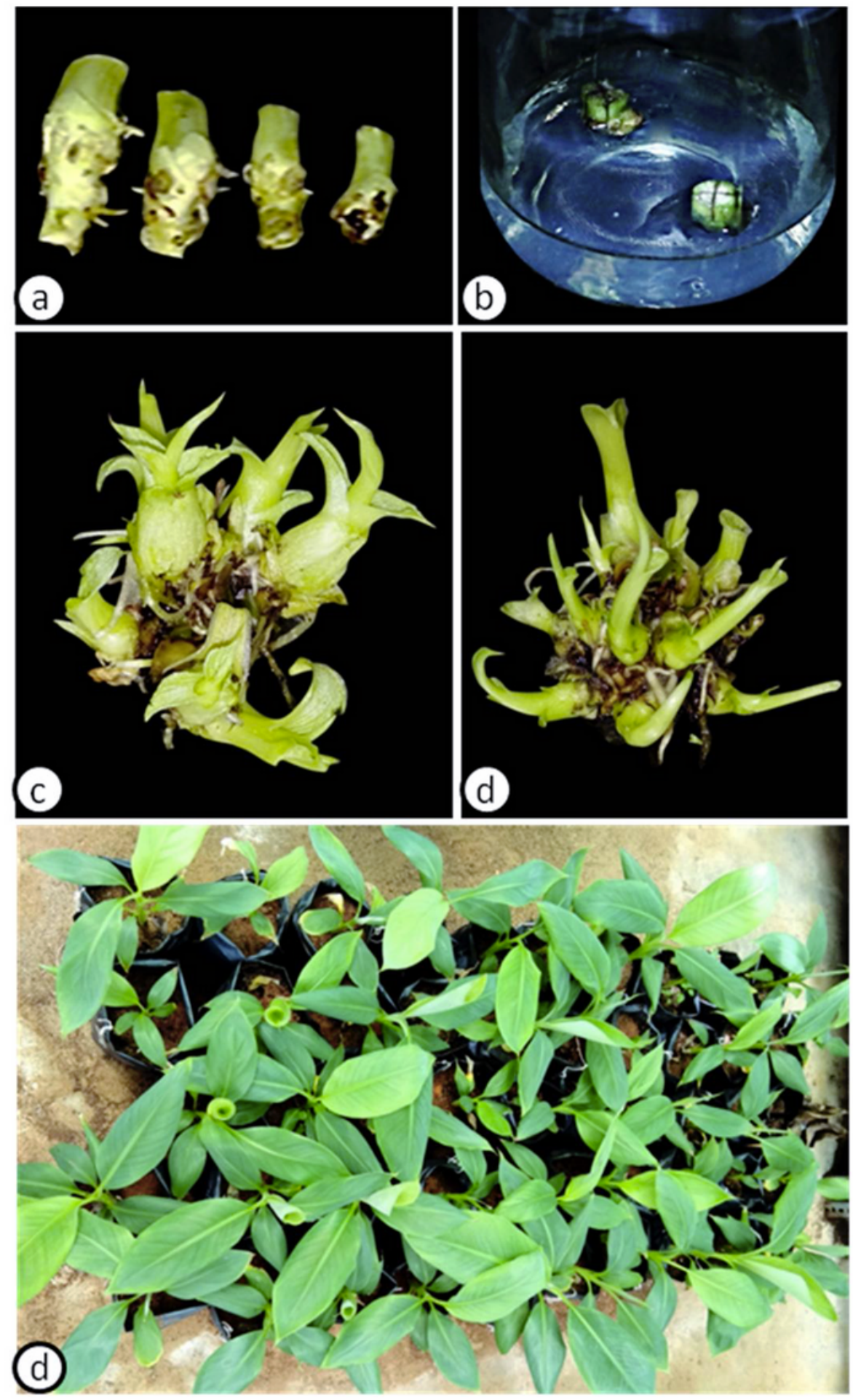

Figure 2

Decorticated explants were subcultured in MS media supplemented with 17.76 $\mu \mathrm{M}$ BAP a- Explants selection based on girth size, b- Decorticated plantlets, c- Multiple shoots observed in 3rd subculture ,dMaximum multiple shoots obtained after 5th subculture, e- Well developed plantlets in secondary hardening 


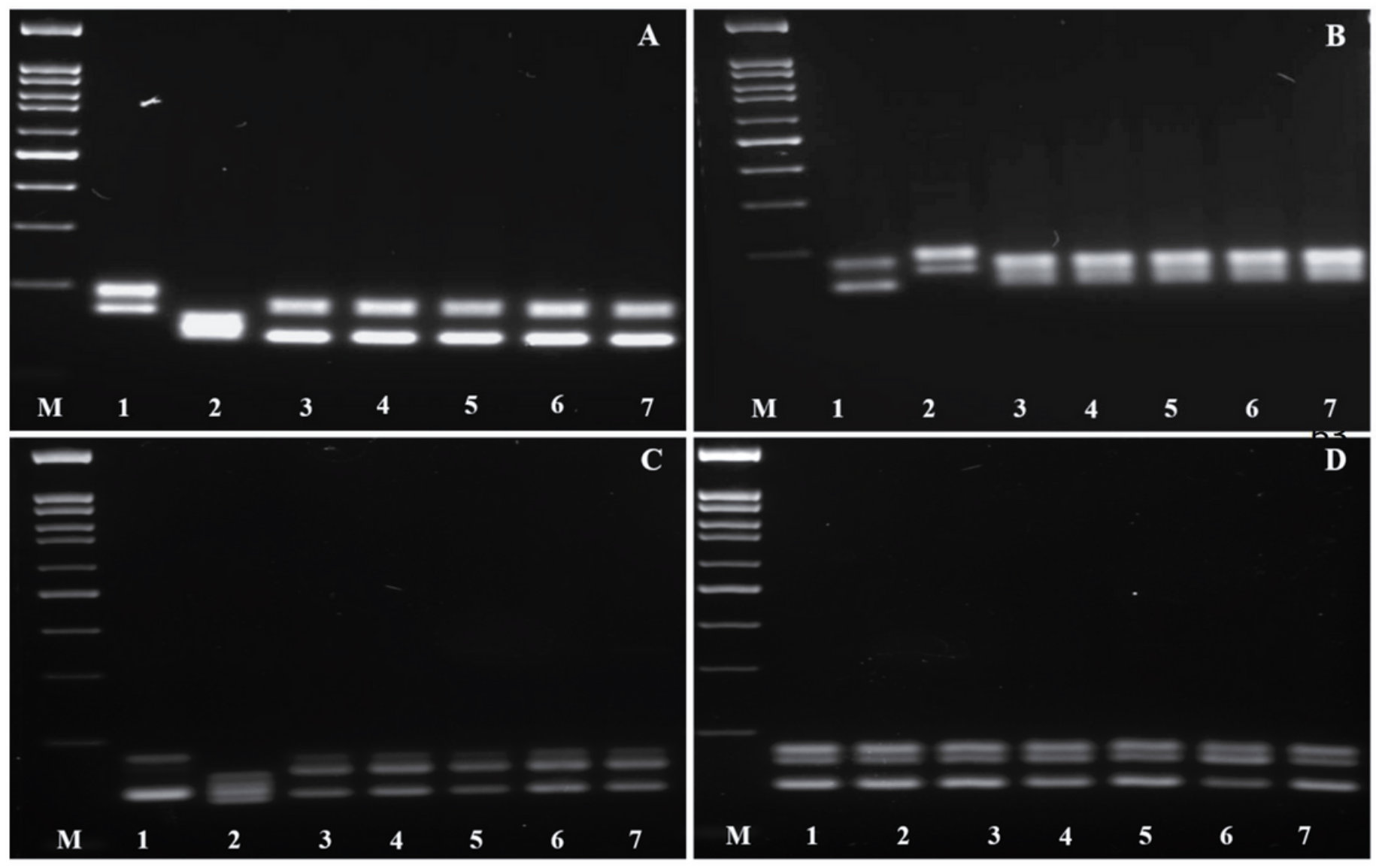

\section{Figure 3}

Confirmation of hybrids and genetic fidelity of multiple shoots derived from shoot tip culture (A) Cultivar Rose x Calcutta 4, (B) Nendran x Cultivar Rose, (D) Nendran X Pisang Jajee, (Lane 1- Female parent, Lane 2-7 Multiple shoots from single embryo) (E) Microcarpa open pollinated. Lane 1-Female parent, Lane 2Male parent, Lane 3 to 7 - Multiple shoots from single embryo.

\section{Supplementary Files}

This is a list of supplementary files associated with this preprint. Click to download.

- Supplementarymaterial1.pdf 